\title{
NOTES
}

\section{Determination of the Order-Disorder Transition Temperature of a Styrene-Isoprene-Styrene Triblock Copolymer Using Dynamic Viscoelastic Measurements and Small-Angle X-Ray Scattering Technique}

\author{
Chang Dae Han ${ }^{\dagger}$ Deog Man BaEK, Shinichi SaKurai, \\ and Takeji HASHIMOTO* \\ Department of Chemical Engineering, Polytechnic University, \\ Brookiyn, New York 11201, U.S.A. \\ * Department of Polymer Chemistry, Faculty of Engineering, \\ Kyoto University, Kyoto 606, Japan
}

(Received March 14, 1989)

\begin{abstract}
KEY WORDS Block Copolymer / Dynamic Viscoelastic Measurement / Interaction Parameter / Order-Disorder Transition Temperature / SmallAngle X-Ray Scattering /
\end{abstract}

A number of research groups have reported measurements of the order-disorder transition temperature $\left(T_{\mathrm{r}}\right)$ of styrene-based block copolymers. $^{1-19}$ Here we define the $T_{\mathrm{r}}$ as the threshold temperature at which the microdomain structure in a block copolymer disappears completely, forming a homogeneous (or disordered) phase as the temperature is increased.

Basically, two experimental techniques have been used to determine the $T_{\mathrm{r}}$ of block copolymers. They are (a) the scattering of electromagnetic radiation and (b) a rheological technique. Hashimoto and co-workers ${ }^{1-7}$ and Roe and co-workers ${ }^{8-10}$ have used small-angle X-ray scattering (SAXS) and Bates and Hartney ${ }^{11}$ have used small-angle neutron scattering (SANS). In the analysis of experimental data, they relied on Leibler's theory ${ }^{20}$ according to which the reciprocal of SAXS intensity $(1 / I)$ should be a linear function of the interaction parameter $\chi \cdot{ }^{21}$ If $\chi$ is assumed to be proportional to the reciprocal of absolute tem- perature $(1 / T)$,

$$
\chi=A+B / T
$$

where $A$ and $B$ are constants, then Leibler's theory predicts that in the disordered state of a block copolymer, the plot of $1 /$ I versus $1 / T$ should be a straight line, i.e.,

$$
1 / I=F(x) / N-2 A-2 B / T
$$

where $F(x)$ is given by eq IV-6 in Leibler's paper $^{20}$ and is independent of temperature, and $N$ is the polymerization index of the block copolymer.

In the use of a rheological technique to determine the $T_{\mathrm{r}}$ of block copolymers, some investigators $^{12}$ used the temperature at which Newtonian behavior is first observed when the temperature is increased, while others ${ }^{13-16}$ used the temperature at which the dynamic storage modulus drops very rapidly when the temperature is increased. Very recently, Han and co-workers ${ }^{17-19}$ have proposed the use of logarithmic plots of dynamic storage modulus

\footnotetext{
† To whom all correspondence should be addressed.
} 
$G^{\prime}(\omega)$ versus dynamic loss modulus $G^{\prime \prime}(\omega)$ to determine the $T_{\mathrm{r}}$ of block copolymers; specifically, the $T_{\mathrm{r}}$ of a block copolymer can be determined by the temperature at which $\log G^{\prime}$ versus $\log G^{\prime \prime}$ plots cease to vary with temperature when the temperature of the block copolymer is increased. The rationale behind the use of this method lies in the fact, that $\log G^{\prime}$ versus $\log G^{\prime \prime}$ plots have been observed to be virtually independent of temperature for homopolymers, polymer blends, and grafted copolymers. ${ }^{23-28}$ Han and Jhon $^{25}$ explained such experimental observations for linear, flexible homopolymers, in terms of molecular theory.

So far, no attempt has been reported in the literature, which was directed at comparing the values of $T_{\mathrm{r}}$ of block copolymers, determined by one experimental technique, against ones determined by other experimental techniques, except for some earlier analyses reported by Widmaier and Meyer, ${ }^{15}$ Kraus and Hashimoto, ${ }^{29}$ Hashimoto et al., ${ }^{4}$ and Watanabe et al. ${ }^{30}$ Very recently, we have undertaken a project to determine the $T_{\mathrm{r}}$ of a styrene-based triblock copolymer, by using a rheological technique in one laboratory and SAXS in another laboratory. In this paper we report our findings.

\section{EXPERIMENTAL}

A polystyrene-block-polyisoprene-blockpolystyrene (SIS) copolymer was synthesized via anionic polymerization. In the polymerization, $s$-butyllithium was used as initiator to first polymerize styrene monomer anionically and then to copolymerize isoprene monomer with this "living" polystyrene to form polystyrene-block-polyisoprene (SI) copolymer. The latter was then reacted with the stoichiometric amount of 1,2-dibromoethane needed to remove the lithium from chain ends as lithium bromide, and to couple the SI diblock copolymers into linear SIS triblock copolymers.
Using gel permeation chromatography (GPC), the segment molecular weights of the block copolymer were determined to be 7400S-99000I-7400S. A very small amount (less than $1 \mathrm{wt} \%$ ) of "dead" polystyrene homopolymer was found to be present.

Spectroscopic analysis indicated that the polyisoprene had about $6 \mathrm{wt} \% 3,4$-polyisoprene, about $94 \mathrm{wt} \%$ 1,4-polyisoprene, and no detectable amount of 1,2-polyisoprene in the SIS block copolymer.

Samples were prepared by first dissolving predetermined amount of SIS block copolymer $(10 \mathrm{wt} \%)$ in toluene in the presence of an antioxidant (IRGANOX ${ }^{\circledR}$ 1010, Ciba-Geigy Group) and then slowly evaporating the solvent. The evaporation of solvent was carried out initially in open air at room temperature for one week and then in a vacuum oven at $40^{\circ} \mathrm{C}$ for three days. The last trace of solvent was removed by drying the samples in a vacuum oven at an elevated temperature by gradually raising the oven temperature up to $110^{\circ} \mathrm{C}$. The drying of the samples was continued, until there was no further change in weight. Finally, the samples were annealed at $130^{\circ} \mathrm{C}$ for $10 \mathrm{~h}$.

A Model R16 Weissenberg rheogoniometer (Sangamo Control Inc.) in the cone-and-plate mode ( $25 \mathrm{~mm}$ diameter plate and 4 degree cone angle with a $160 \mu \mathrm{m}$ gap) was used to measure the dynamic storage and loss moduli, $G^{\prime}(\omega)$ and $G^{\prime \prime}(\omega)$, as functions of angular frequency $(\omega)$ at various temperatures for the block copolymer. Data acquisition was accomplished with the aid of a microcomputer interfaced with the rheometer. The temperature control was accurate to within $\pm 1{ }^{\circ} \mathrm{C}$. In the rheological measurements a fixed strain was used at a given temperature. Specifically, the strain was varied from $0.03 \%$ at $120^{\circ} \mathrm{C}$ to $0.3 \%$ at $230^{\circ} \mathrm{C}$, which were well within the linear viscoelastic range of the materials investigated. All experiments were conducted under a nitrogen blanket in order to avoid oxidative degradation of the samples. 
Small-angle X-ray scattering (SAXS) experiments were conducted with an apparatus, described in detail elsewhere, ${ }^{31}$ which consists of a $12 \mathrm{~kW}$ rotating-anode $\mathrm{X}$-ray generator, a graphite crystal for incident-beam monochromatization, a $1.5 \mathrm{~m}$ camera, and a onedimensional, position-sensitive, proportional counter. $\mathrm{Cu} K_{\alpha}$ line $(\lambda=1.54 \AA)$ was used. The SAXS profiles were corrected for absorption, air scattering, background scattering arising from thermal diffuse scattering, and slit-height and slit-width smearings. ${ }^{32}$

The SAXS profiles were measured as a function of temperature using the temperature enclosure as described elsewhere. ${ }^{1}$ The profiles shown in this paper were obtained by preheating the solvent-cast and dried film specimen at $210^{\circ} \mathrm{C}$ for about $1 \mathrm{~h}$, in order to erase the thermal history encountered by the solvent casting process. Note that this temperature, $210^{\circ} \mathrm{C}$, is higher than the $T_{\mathrm{r}}$ (about $180^{\circ} \mathrm{C}$ ) of the specimen, which is reported below. The specimen was then cooled down to each measurement temperature and held there, prior to SAXS measurements, for at least $0.5 \mathrm{~h}$ in order to ensure that thermal equilibrium was achieved.

\section{RESULTS AND DISCUSSION}

Figure 1 gives $\log G^{\prime}(\omega)$ versus $\log \omega$ plots, and Figure 2 gives $\log G^{\prime \prime}(\omega)$ versus $\log \omega$ plots, for the block copolymer used at twelve different temperatures: $120,130,140,150,160$, $170,180,190,200,210,220$, and $230^{\circ} \mathrm{C}$. It can be seen in Figures 1 and 2 that values of $G^{\prime}$ and $G^{\prime \prime}$ decrease gradually as the temperature is increased from 120 to $230^{\circ} \mathrm{C}$, and that the slope of $\log G^{\prime}$ versus $\log \omega$ increases gradually with increasing temperature. Note that the slopes of the $\log G^{\prime}$ versus $\log \omega$ plots are virtually the same at temperatures of about $180^{\circ} \mathrm{C}$ and above. The data from Figures 1 and 2 were used to prepare $\log G^{\prime}$ versus $\log G^{\prime \prime}$ plots, which are given in Figure 3. It can be seen in Figure 3 that at a fixed value of $G^{\prime \prime}, G^{\prime}$

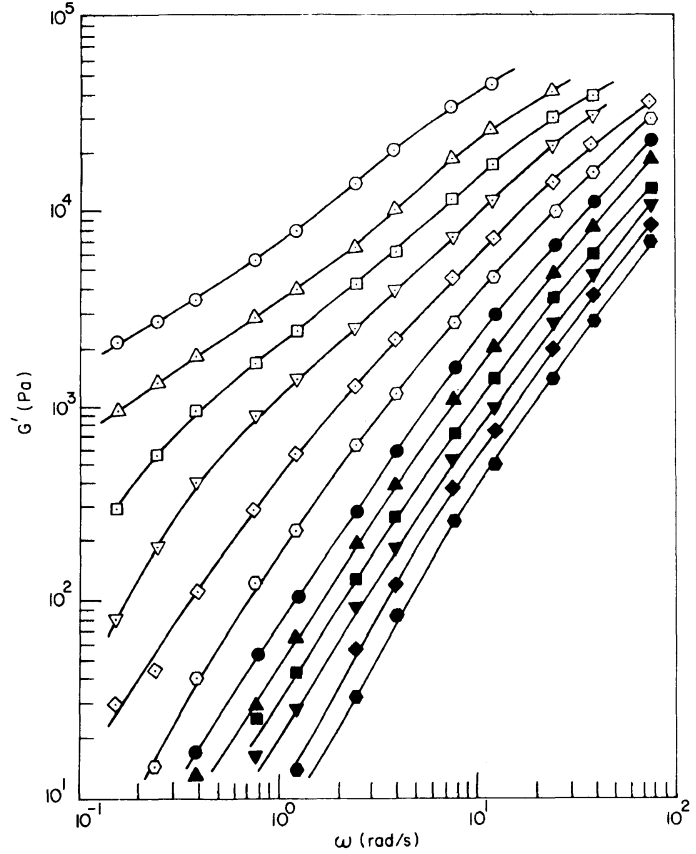

Figure 1. $\log G^{\prime}$ versus $\log \omega$ for the SIS block copolymer at various temperatures $\left({ }^{\circ} \mathrm{C}\right):(\odot) 120 ;(\triangle) 130$;

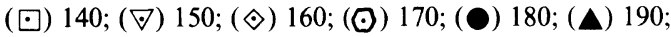

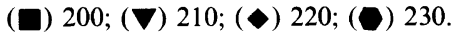

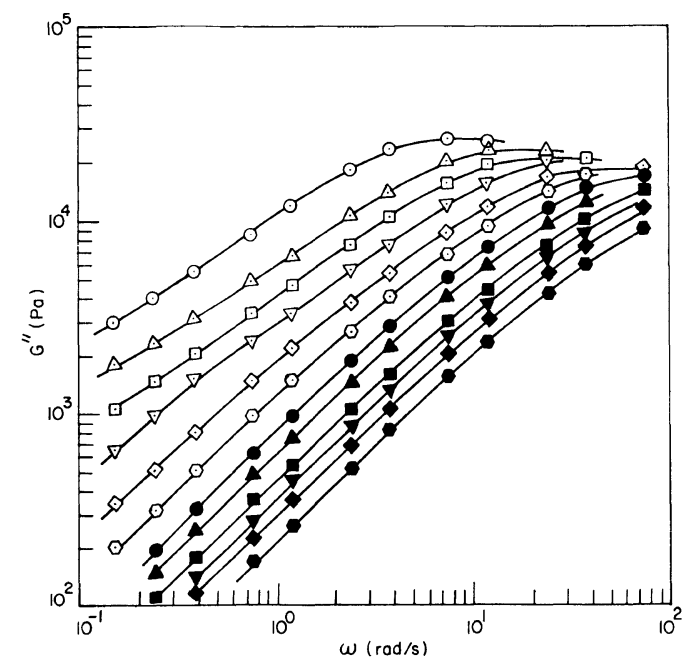

Figure 2. $\log G^{\prime \prime}$ versus $\log \omega$ for the SIS block copolymer at various temperatures. Symbols are the same as in Figure 1. 


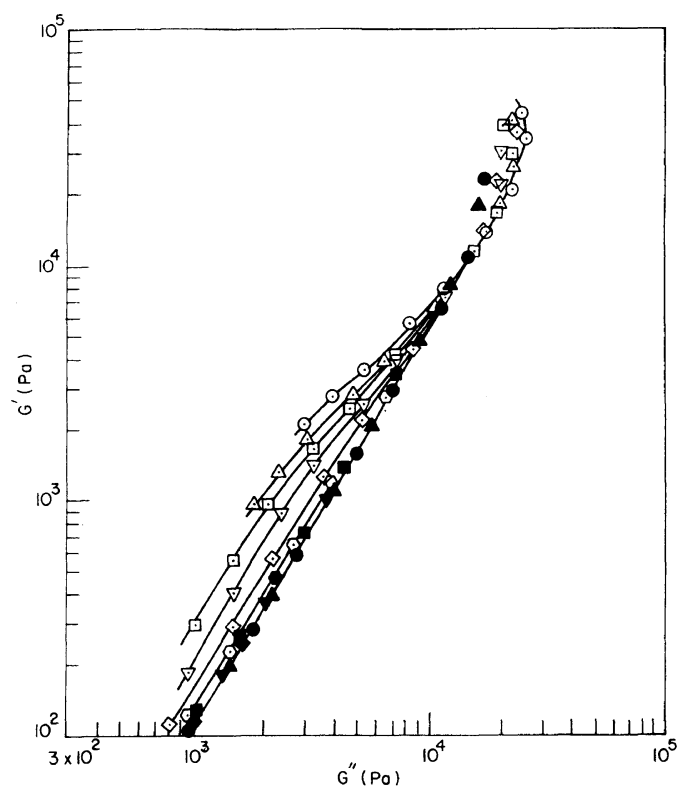

Figure 3. $\log G^{\prime}$ versus $\log G^{\prime \prime}$ for the SIS block copolymers at various temperatures. Symbols are the same as in Figure 1.

decreases gradually as the temperature is increased from 120 to $180^{\circ} \mathrm{C}$ and then remains constant, independent of temperature at $180^{\circ} \mathrm{C}$ and above. In other words, $180^{\circ} \mathrm{C}$ is the lowest temperature, at which $\log G^{\prime}$ versus $\log G^{\prime \prime}$ plots for the block copolymer used cease to vary with temperature. According to the criterion suggested by $\mathrm{Han}$ and co-workers, ${ }^{17-19}$ we can conclude from Figure 3 that the $T_{\mathrm{r}}$ of this block copolymer is about $180^{\circ} \mathrm{C}$.

Figure 4 gives SAXS intensity profiles for the block copolymer used at various temperatures, and Figure 5 gives plots of the reciprocal of SAXS intensity $(1 / I)$ versus the reciprocal of absolute temperature $(1 / T)$. It can be seen in Figure 5 that by applying the criterion given by eq 2 , the $T_{\mathrm{r}}$ of this block copolymer is about $180^{\circ} \mathrm{C}$, which is in remarkably good agreement with the value determined by the rheological technique, shown in Figure 3.

It should be pointed out, however, that the value of $T_{\mathrm{r}}$ determined by the rheological method is accurate to within $10^{\circ} \mathrm{C}$. The results

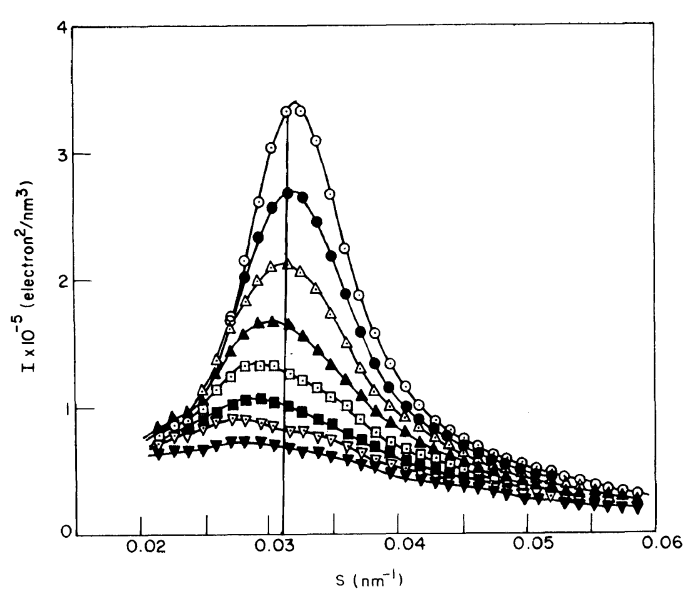

Figure 4. SAXS intensity profiles for the SIS block copolymer at various temperatures $\left({ }^{\circ} \mathrm{C}\right):(\odot)$ 140; $(\mathrm{O})$

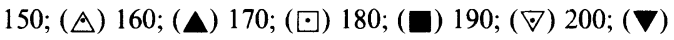
210. The data were obtained during the cooling process, and $s=(2 / \lambda) \sin \theta$ is the magnitude of the scattering vector, $\lambda$ and $\theta$ being the wavelength of $\mathrm{X}$-ray and one half of the scattering angle, respectively. The nearly vertical straight line in the figure represents the change of the peak position expected from thermal expansion only.

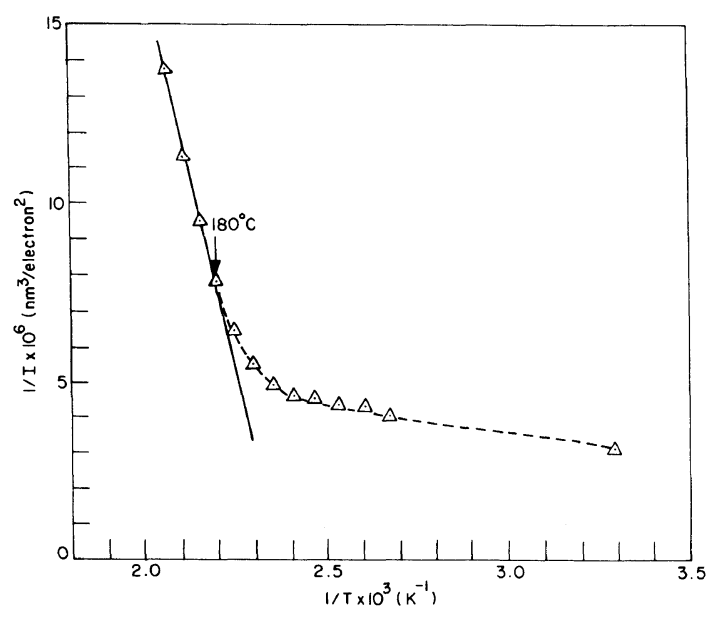

Figure 5. Reciprocal SAXS intensity versus reciprocal absolute temperature at $s=2.825 \times 10^{-2} \mathrm{~nm}^{-1}$.

of SAXS performed by both heating and cooling the sample indicate that the $T_{\mathrm{r}}$ of the block copolymer lies somewhere between 170 and $180^{\circ} \mathrm{C}$. It is encouraging to observe that the two vastly different types of experimental techniques gave rise to virtually the same value of 
$T_{\mathrm{r}}$ for the block copolymer investigated.

It is worth commenting on Figure 4, namely, noting the direction toward which the scattering peak position is shifted along the axis of scattering vector $s=(2 / \lambda) \sin \theta$, as the temperature is varied. Here, $2 \theta$ and $\lambda$ are the scattering angle and wavelength of $\mathrm{X}$-ray, respectively. We have observed almost the same trend in the shift of the scattering peak position during the heating process, i.e., when the specimen was heated from room temperature to $210^{\circ} \mathrm{C}$ which is above the $T_{\mathrm{r}}$ of the specimen. Note, however, that the shift of the scattering peak position observed in Figure 4 is slightly larger than that expected from the consideration of thermal expansion, which is shown by a nearly vertical straight line there. The nearly vertical straight line in Figure 4 is drawn using the expression:

$$
s_{\mathrm{m}, \mathrm{T}}=s_{\mathrm{m}, 160}[1+\beta(T-160)]^{-1 / 3}
$$

where $s_{\mathrm{m}, \mathrm{T}}$ and $s_{\mathrm{m}, 160}$ are the magnitudes of the scattering vector $s$ at the peak position at temperature $T$ and at $160^{\circ} \mathrm{C}$, respectively, and $\beta$ is the thermal expansion coefficient, which in the present case is $6.7 \times 10^{-4}(1 / K)$, above the glass transition temperature. For all intents and purposes, the peak positions appearing in Figure 4 can be regarded as being nearly independent of temperature within the limits of experimental accuracy.

When a system attains thermal equilibrium, the value of $s_{\mathrm{m}, \mathrm{T}}$ is expected to remain constant for $T>T_{\mathrm{r}}$, but to decrease with lowering temperature for $T \leqq T_{\mathrm{r}}$, owing to the onset of $\mathrm{mi}$ crodomain formation and subsequent growth of the microdomains due to an increasing segregation effect. ${ }^{2,33,34}$ However, the shift of $s_{\mathrm{m}, \mathrm{T}}$ observed in Figure 4 , by increasing (or decreasing) temperature shows a trend quite opposite to what is normally expected. This seemingly peculiar behavior may be attributable to the unique feature of the SIS block copolymer under investigation, namely, relatively small amounts (about $13 \mathrm{wt} \%$ ) of a polystyrene phase with a spherical micro- domain structure in the ordered state (i.e., for $T \leqq T_{\mathrm{r}}$ ). We offer the following explanation of this experimental observation.

When the temperature of the SIS block copolymer under consideration is lowered below its $T_{\mathrm{r}}$, the thermodynamic driving force for microphase segregation increases, which would then make the spherical microdomains grow and, also, the intersphere distances increase. However, the growth of the spherical microdomains in the SIS block copolymer might have been hindered kinetically since the mutual diffusion of the block copolymer may be very much suppressed due to a very high kinetic barrier associated with the enthalpy of mixing, which is proportional to $\chi N$ (see Figure 9 of ref 35). Thus, once spherical microdomains are formed in a highly asymmetric block copolymer, they may essentially be locked in with further growth of the microdomains being very difficult with decreasing temperature. This nonequilibrium aspect of the growth of spherical microdomains with decreasing temperature may give rise to a nearly constant value of $s_{\mathrm{m}, \mathrm{T}}$. Although the shift of $s_{\mathrm{m}, \mathrm{T}}$ observed in Figure 4, with respect to a variation of temperature, appears to be slightly larger than that predicted from the consideration of thermal expansion, we feel that the difference may lie within the experimental accuracy for the highly asymmetric SIS block copolymer investigated.

Acknowledgment. The Kyoto group wishes to acknowledge the financial support received from the Yokohama Rubber Co., Ltd., Japan.

\section{REFERENCES AND NOTES}

1. T. Hashimoto, Y. Tsukahara, and H. Kawai, J. Polym. Sci., Polym. Lett. Ed., 18, 585 (1980); Macromolecules, 14, 708 (1981).

2. T. Hashimoto, M. Shibayama, and H. Kawai, Polym. Prepr., Am. Chem. Soc., Div. Polym. Chem., 23, 21 (1982); Macromolecules, 16, 1093 (1983).

3. T. Hashimoto, Y. Tsukahara, and H. Kawai, Polym. J., 15, 699 (1983).

4. T. Hashimoto, M. Shibayama, H. Kawai, H. 
Watanabe, and T. Kotaka, Macromolecules, 16, 361 (1983).

5. K. Mori, H. Hasegawa, and T. Hashimoto, Polym. J., 17, 799 (1985).

6. T. Hashimoto, K. Kowsaka, M. Shibayama, and H. Kawai, Macromolecules, 19, 754 (1986).

7. T. Hashimoto, Y. Ijichi, and L. J. Fetters, J. Chem. Phys., 89, 2463 (1988); Y. Ijichi, T. Hashimoto, and L. J. Fetters, Macromolecules, in press.

8. R. J. Roe, M. Fishkis, and J. C. Chang, Macromolecules, 14, 1091 (1981).

9. W. C. Zin and R. J. Roe, Macromolecules, 17, 183 (1984).

10. S. Nojima and R. J. Roe, Macromolecules, 20, 1866 (1987).

11. F. S. Bates and M. A. Hartney, Macromolecules, 18, 2478 (1985).

12. C. I. Chung and J. C. Gale, J. Polym. Sci., Polym. Phys. B, 14, 1149 (1976).

13. C. I. Chung and M. I. Lin, J. Polym. Sci., Polym. Phys. B, 16, 545 (1978).

14. E. V. Gouinlock and R. S. Porter, Polym. Eng. Sci., 17, 534 (1977).

15. J. M. Widmaier and G. C. Meyer, J. Polym. Sci., Polym. Phys. B, 18, 2217 (1980).

16. F. S. Bates, Macromolecules, 17, 2607 (1984).

17. C. D. Han and J. Kim, J. Polym. Sci., Polym. Phys. $B, 25,1741$ (1987).

18. J. Kim, C. D. Han, and S. G. Chu, J. Polym. Sci., Polym. Phys. B, 26, 677 (1988).

19. C. D. Han, J. Kim, and J. K. Kim, Macromolecules, 22, 383 (1989).

20. L. Leibler, Macromolecules, 13, 1602 (1980).

21. The Leibler theory is based on a mean-field theory, which is rigorous at infinitely large molecular weight. A correction for finite molecular weights gives a nonlinear dependence of $1 / I$ on $\chi^{22}$

22. G. H. Fredrickson and E. Helfand, J. Chem. Phys., 87, 697 (1987).

23. C. D. Han and K. W. Lem, Polym. Eng. Rev., 2, 135 (1983).

24. C. D. Han, J. Appl. Polym. Sci., 35, 167 (1988).

25. C. D. Han and M. S. Jhon, J. Appl. Polym. Sci., 32, 3809 (1986).

26. H. K. Chuang and C. D. Han, J. Appl. Polym. Sci., 29, 2205 (1984).

27. C. D. Han and H. K. Chuang, J. Appl. Polym. Sci., 30, 2431 (1985).

28. C. D. Han and H. H. Yang, J. Appl. Polym. Sci., 33, 1199 (1987).

29. G. Kraus and T. Hashimoto, J. Appl. Polym. Sci., 27, 1745 (1982).

30. H. Watanabe, T. Kotaka, T. Hashimoto, M. Shibayama, and H. Kawai, J. Rheol., 26, 153 (1982).

31. T. Hashimoto, S. Suehiro, M. Shibayama, K. Saijo, and H. Kawai, Polym. J., 13, 501 (1981); S. Suehiro, K. Saijo, Y. Ohta, T. Hashimoto, and H. Kawai, Anal. Chim. Acta, 189, 41 (1986).

32. M. Fujimura, T. Hashimoto, and H. Kawai, Mem. Fac. Eng. Kyoto Univ., 43, 224 (1981).

33. T. Hashimoto, M. Shibayama, and H. Kawai, Macromolecules, 13, 1237 (1980).

34. T. Hashimoto, in "Thermoplastic Elastomers," N. R. Legge, G. Holden, and H. E. Schroeder, Ed., Hanser, Munich, 1987.

35. M. Shibayama, T. Hashimoto, and H. Kawai, Macromolecules, 16, 1434 (1983). 